Research Article

\title{
Structural Analysis and Reactivity of Tetramethylcopper(III) Complex towards Nitrogen Donor Ligands by Density Functional Theory
}

\author{
Perumal Balu, ${ }^{1}$ Venu Kannappan, ${ }^{2}$ and Rathinavelu Kumar ${ }^{3}$ \\ ${ }^{1}$ Department of Chemistry, Guru Nanak College, Chennai 600 042, India \\ ${ }^{2}$ Department of Chemistry, Presidency College, Chennai 600 005, India \\ ${ }^{3}$ Department of Physics, The New College, Chennai 600 014, India \\ Correspondence should be addressed to Venu Kannappan; vkannappan48@gmail.com
}

Received 28 April 2016; Revised 7 June 2016; Accepted 12 June 2016

Academic Editor: Dheeraj K. Singh

Copyright (C) 2016 Perumal Balu et al. This is an open access article distributed under the Creative Commons Attribution License, which permits unrestricted use, distribution, and reproduction in any medium, provided the original work is properly cited.

\begin{abstract}
DFT studies are carried out on some ligand substitution reactions of tetramethylcuprate(III) (TMC) complex with five different nitrogen donor ligands as probe ligands. The geometry optimization of the possible nine model systems and the frequency calculations are carried out at DFT level using LANL2DZ basis set. The selected structural parameters of optimized model systems of $\mathrm{Cu}$ (III) complexes are reported and discussed. The change in the $\mathrm{M}-\mathrm{C}$ bond distance in TMC due to substitution by probe ligands is explained. Natural population analysis (NPA) has been carried out for these complexes to establish the charge of copper in these complexes. A detailed population analysis of valence orbitals of copper complexes supports the existence of $\mathrm{d}^{8}$ configuration for metal in complexes and there is evidence for the transmission of electrons from the nitrogen donor atom to $\mathrm{d}_{x y}, \mathrm{~d}_{x^{2}-y^{2}}$, and $4 \mathrm{~s}$ orbitals. Bond order calculations have been performed for all the complexes to probe the interaction between $\mathrm{Cu}$ (III) and the ligand. The stability of the complexes is ascertained from the computed chemical hardness. In order to understand the nature of $\mathrm{Cu}$ (III)-L ( $\mathrm{L}=\mathrm{N}$ donors) and $\mathrm{Cu}$ (III)-Me bonds in different complexes, Energy Decomposition Analysis (EDA) has been carried out for all the complexes chosen in the theoretical study. Thermodynamic feasibility of these reactions is investigated in terms of free energy changes of these reactions.
\end{abstract}

\section{Introduction}

The coinage metal copper is listed in group 11 in the periodic table and it occurs in a range of oxidation states $[\mathrm{Cu}(0), \mathrm{Cu}(\mathrm{I})$, $\mathrm{Cu}(\mathrm{II}), \mathrm{Cu}(\mathrm{III})$, and $\mathrm{Cu}(\mathrm{IV})]$. Copper ions in these oxidation states form complexes. Copper complexes in the oxidation states $+1,+2$, and +3 are more common than complexes of $\mathrm{Cu}(0)$ and $\mathrm{Cu}(\mathrm{IV})$. The $\mathrm{Cu}(\mathrm{III})$-alkyl complexes are used for the effective $\mathrm{C}-\mathrm{C}$ bond formation at low temperatures [15] and several $\mathrm{Cu}(\mathrm{III})$-alkyl intermediates have also been characterized by Rapid Injection NMR technique [6-11]. Theoretical studies have been carried out to understand the stability and reactivity of $\mathrm{Cu}(\mathrm{III})$-alkyl complexes [12-16]. Bertz et al. reported the efficient preparation of copper(III) intermediates by using Gilman reagents $\left(\mathrm{Me}_{2} \mathrm{CuLi}\right.$, LiX where $\mathrm{X}=\mathrm{Br}$, I) with 2,3-dichloropropene [17, 18]. Recently, Bertz and Ogle investigated ligand exchange reactions of $\mathrm{CuMe}_{4}$ with $\mathrm{Br}^{-}, \mathrm{CN}^{-}, \mathrm{Ph}_{2} \mathrm{Li}, \mathrm{IMH}, \mathrm{Cl}_{2} \mathrm{O}$, and $\mathrm{Li}^{+} \mathrm{S}^{-} \mathrm{Ph}$ for selective $\mathrm{C}-\mathrm{C}$ bond formation [18]. Gärtner et al. studied the ligand exchange reactions of trimethyl copper(III) with $\mathrm{I}^{-}, \mathrm{Me}^{-}, \mathrm{MeS}^{-}, \mathrm{Cl}^{-}$, and $\mathrm{CN}^{-}$by DFT method [19]. Some neutral organocopper(III)-alkyl complexes have also been reported by the ligand exchange reaction with $\mathrm{PMe}_{3}, \mathrm{PBu}_{3}$, $\mathrm{P}(\mathrm{OMe})_{3}, \mathrm{PPh}_{3}, \mathrm{Py}, \mathrm{DMAP}, \mathrm{MI}, \mathrm{MIB}$, and DBN $[13,19]$. The most notable applications of organocopper reagents are the addition to $\alpha, \beta$-unsaturated carbonyl compounds and their substitution reactions with organic halides [20-22]. The formation of $\mathrm{C}-\mathrm{C}$ bond in these reactions was proposed to 
be mediated by $\mathrm{Cu}$ (III) intermediate and further supported by theoretical studies $[12,15,16]$. However, other reactivity studies such as substitution reactions have not been reported on the ligand substitution reactions of $\mathrm{Cu}$ (III)-alkyl complexes with ligands containing different donor atoms. density functional theory (DFT) calculations showed that the methyl anion is a strong $\sigma$-donor ligand that affords the largest stabilization energy in comparison to halides, thiolate and cyanide anions [19]. In this paper, we report the results obtained in the theoretical investigation of some substitution reactions of TMC complex with nitrogen containing ligands being reported and discussed. In the present study the ligands used are all negative ligands $\left(\mathrm{N}^{3-}, \mathrm{NH}^{2-},{ }^{-} \mathrm{NHCH}_{2}-\right.$ $\mathrm{CH}_{2} \mathrm{NH}^{-},{ }^{-} \mathrm{NHC}_{6} \mathrm{H}_{4} \mathrm{NH}^{-}$, and $\mathrm{NH}_{2}{ }^{-}$) so that they are strong enough to substitute methyl group in TMC complex. Natural population analysis and bond order calculations have been performed for all the complexes to establish the charge on the metal atom and understand the metal ion-ligand interactions in these complexes. The feasibility of these ligand substitution reactions is investigated in terms of computed free energy changes.

\section{Computational Methods}

The geometries of nine complexes (1-9) were fully optimized using the hybrid density functional theory (B3LYP). Carbon, nitrogen, and hydrogen were described using the 6-31G ${ }^{*}$ basis set. Copper atom was described using the LANL2DZ basis set [23-29]. Vibrational frequency analysis has been performed on the optimized structures of the copper complexes to ensure the stationary point and it is to be noted that no negative frequencies were obtained. Natural population analysis (NPA) was performed using the same level of theory and same basis sets. All the computational procedures were used as implemented in the Gaussian-03 package [30]. Energy decomposition analysis was performed at the GGA: PBE/TZ2P level using Amsterdam Density Functional (ADF) program package [31]. Scalar relativistic effects have been considered by using the zero-order regular approximation [32].

\section{Results and Discussion}

3.1. General Considerations and Optimization of the Complexes. All the cuprate(III) complexes (1-9) have been optimized to the square planar geometry around the $\mathrm{Cu}$ (III) center and it may be pointed out that no imaginary frequencies were obtained in the computation. The bond lengths and bond angles of the nine copper(III) complexes are listed in Table 1.

Structure of the nine $\mathrm{Cu}$ (III)-methyl complexes 1-9 has been optimized at DFT level using 6-31G* and LANL2DZ basis sets. Complexes 2-9 have generally one non-methyl ligand (which is called probe ligand (L)) out of the four ligands. We have defined the cis/trans-positions in complexes 2-9 with respect to the probe ligand as described in Figure 1. Analysis of data in Table 1 indicates that there is change in the $\mathrm{Cu}$ (III)-C bond length as well as $\mathrm{Cu}-\mathrm{L}$ ( $\mathrm{L}=$ probe ligand) when the methyl ligand in tetramethylcuprate(III) complex is replaced by the probe ligand. The $\mathrm{Cu}-\mathrm{C}$ bond length in complex $\mathbf{1}\left(\left[\mathrm{M}\left(\mathrm{CH}_{3}\right)_{4}\right]^{-1}\right)$ is computed and the value is $2.02 \AA$ which is similar to what has been reported by earlier researchers $[33,34]$. The bond angle $\mathrm{C}-\mathrm{Cu}-\mathrm{C}$ obtained for complex 1 is close to $180^{\circ}$ suggesting that the tetramethylcuprate(III) complex has square planar geometry.

The change in the $\mathrm{Cu}-\mathrm{C}$ distance in the complexes investigated depends on the probe ligand. When the charge on the anion probe ligand is higher, the change in the metal$\mathrm{C}_{\text {trans }}$ bond distance is more. Thus for the nitride $\left(\mathrm{N}^{3-}\right)$ probe ligand, the $\mathrm{Cu}-\mathrm{C}_{\text {trans }}$ bond length is $2.08 \AA$ and for the imido ligand $\left(\mathrm{NH}^{2-}\right)$ the $\mathrm{Cu}-\mathrm{C}_{\text {trans }}$ bond length is $2.07 \AA$. In the case of amido $\left(\mathrm{NH}_{2}{ }^{-}\right)$complex $7, \mathrm{Cu}-\mathrm{C}_{\text {trans }}$ bond length is $2.02 \AA$ which is the same as in complex 1 . However, there is not much change in $\mathrm{Cu}-\mathrm{C}_{\text {cis }}$ distance as the methyl ligand is replaced by probe ligand. It may be mentioned here that the complex cis $\left[\mathrm{Cu}(\mathrm{NH})_{2}\left(\mathrm{CH}_{3}\right)_{2}\right]^{3-}$ is not stable and its geometry could not be optimized and only the optimized geometry of transisomer was obtained. We found that the $\mathrm{Cu}-\mathrm{L}$ bond length is also influenced by the probe ligand. It is found that for the nitride probe ligand the $\mathrm{Cu}-\mathrm{L}$ bond length is shorter while in the case of other probe ligands, the $\mathrm{Cu}-\mathrm{L}$ bond length is slightly longer. It is also found that $\mathrm{Cu}-\mathrm{L}$ bond distance is shorter than $\mathrm{Cu}-\mathrm{C}$ distance in complex 1 . The $\mathrm{L}-\mathrm{Cu}-\mathrm{L}$ bond angles presented in Table 1 suggest that there is only slight change in the bond angle due to replacement of alkyl ligand by the probe ligands.

3.2. Charge Distribution in the Cu(III)-Alkyl Complexes. Natural population analysis (NPA) was carried out for complexes 1-9 and the results are given in Table 2. It is observed that cis-methyl carbon atom carries a more negative charge than the trans-methyl carbon of the alkyl group in all complexes $1-9$. Both cis- and trans-methyl carbon atoms in complexes 1-9 are negatively charged and establish the anionic nature of the alkyl ligand in all the complexes investigated. It may be noted that the charge on the alkyl carbon atom is not varied significantly when we change the probe ligand. The calculated natural charge on the copper atom in all the complexes is close to +1 and in complexes 2 and 4 small negative charge is obtained. The computed electron population in the central ion in complexes 1-9 is more than the expected value in $\mathrm{Cu}$ (III) with $\mathrm{d}^{8}$ electronic configuration, respectively [31].

The calculated formal charge on the metal ion in the complexes was lower than the formal charge +3 , confirming a significant charge donation from the ligands containing nitrogen donor atom. This confirms the electron transmission of donor atoms toward the central metal. This is also supported by the variation in the charge on donor atom of ligand in different complexes.

$\mathrm{Cu}$ (III) consequently draws the electron density from the negative ligands surrounding copper center and hence the charge on copper is less than +3 [14, 33-37]. Similar behavior was observed by earlier researchers in $\mathrm{Ni}$ (II) complexes with square planar geometry [38].

A detailed population analysis of valance orbitals of copper has been carried out on complexes 1-9 to establish the electronic configuration of the central metal atom in 


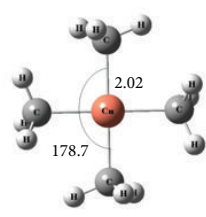

$\left[\mathrm{Cu}\left(\mathrm{CH}_{3}\right)_{4}\right]^{-1}$

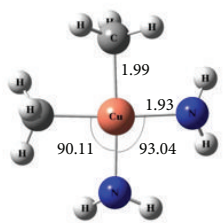

$\left[\mathrm{Cu}\left(\mathrm{NH}_{2}\right)_{2}\left(\mathrm{CH}_{3}\right)_{2}\right]^{-1}$

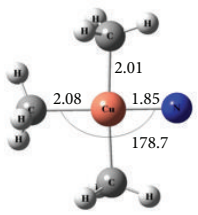

$\left[\mathrm{CuN}\left(\mathrm{CH}_{3}\right)_{3}\right]^{3-}$

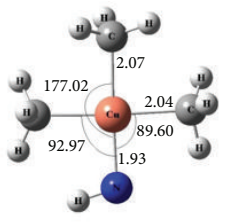

$\left[\mathrm{Cu}(\mathrm{NH})\left(\mathrm{CH}_{3}\right)_{3}\right]^{2-}$

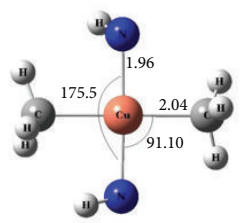

$\left[\mathrm{Cu}(\mathrm{NH})_{2}\left(\mathrm{CH}_{3}\right)_{2}\right]^{3-} \quad\left[\mathrm{Cu}\left(\mathrm{NH}_{2}\right)\left(\mathrm{CH}_{3}\right)_{3}\right]^{-1}$

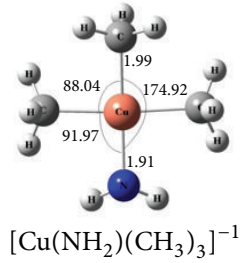

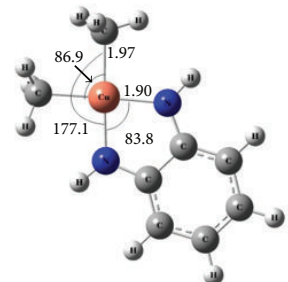

$\left[\mathrm{Cu}(\mathrm{NH})_{2} \mathrm{C}_{6} \mathrm{H}_{4}\left(\mathrm{CH}_{3}\right)_{2}\right]^{-1}$

FIGURE 1: Optimized geometries for copper(III) complexes with nitrogen.

TABLE 1: Selected bond lengths $(\AA)$ and bond angles $\left(^{\circ}\right)$ of copper III complexes with nitrogen.

\begin{tabular}{|c|c|c|c|c|}
\hline \multirow{2}{*}{\multicolumn{2}{|c|}{ Complexes }} & \multicolumn{2}{|c|}{ Bond length $(\AA)$} & \multirow{2}{*}{$\begin{array}{c}\text { Bond angle }\left(^{\circ}\right) \\
\text { L-Cu-L }\end{array}$} \\
\hline & & $\mathrm{Cu}-\mathrm{C}$ & $\mathrm{Cu}-\mathrm{L}$ & \\
\hline$\left[\mathrm{Cu}\left(\mathrm{CH}_{3}\right)_{4}\right]^{-1}$ & (1) & 2.02 & & \\
\hline$\left[\mathrm{CuN}\left(\mathrm{CH}_{3}\right)_{3}\right]^{3-}$ & (2) & $\begin{array}{l}2.01_{\text {cis }} \\
2.08_{\text {trans }}\end{array}$ & $1.85(\mathrm{~N})$ & \\
\hline$\left[\mathrm{Cu}(\mathrm{NH})\left(\mathrm{CH}_{3}\right)_{3}\right]^{2-}$ & (3) & $\begin{array}{l}2.04_{\text {cis }} \\
2.07_{\text {trans }}\end{array}$ & $1.93(\mathrm{NH})$ & \\
\hline $\operatorname{trans}\left[\mathrm{Cu}(\mathrm{NH})_{2}\left(\mathrm{CH}_{3}\right)_{2}\right]^{3-}$ & (4) & 2.04 & $1.96(\mathrm{NH})$ & $175.5(\mathrm{NH})$ \\
\hline$\left[\mathrm{Cu}\left(\mathrm{NH}_{2}\right)\left(\mathrm{CH}_{3}\right)_{3}\right]^{-1}$ & (5) & 1.99 & $1.91\left(\mathrm{NH}_{2}\right)$ & 174.92 \\
\hline $\operatorname{cis}\left[\mathrm{Cu}\left(\mathrm{NH}_{2}\right)_{2}\left(\mathrm{CH}_{3}\right)_{2}\right]^{-1}$ & (6) & 1.99 & $1.93\left(\mathrm{NH}_{2}\right)$ & 93.04 \\
\hline $\operatorname{trans}\left[\mathrm{Cu}\left(\mathrm{NH}_{2}\right)_{2}\left(\mathrm{CH}_{3}\right)_{2}\right]^{-1}$ & (7) & 2.02 & $1.90\left(\mathrm{NH}_{2}\right)$ & 179.17 \\
\hline$\left[\mathrm{Cu}\left(\mathrm{NHCH}_{2}-\mathrm{CH}_{2} \mathrm{NH}\right)\left(\mathrm{CH}_{3}\right)_{2}\right]^{-1}$ & (8) & 2.00 & $1.90(\mathrm{NH})$ & 85.79 \\
\hline$\left[\mathrm{Cu}(\mathrm{NH})_{2} \mathrm{C}_{6} \mathrm{H}_{4}\left(\mathrm{CH}_{3}\right)_{2}\right]^{-1}$ & (9) & 1.97 & $1.90(\mathrm{NH})$ & 83.81 \\
\hline
\end{tabular}

these complexes and also to identify the extent of electronic transmission from the donor atom of the ligand to the central metal atom and the computational results are presented in Table 3. It may be mentioned here that the electron density in $4 \mathrm{p}$ orbital of the metal ion is less than 0.005 in all the complexes and hence these values are not given. The theoretical d-orbital occupation orders for the copper are quite similar, with the lowest population of the $\mathrm{d}_{x^{2}-y^{2}}$ orbital. The values of the $\mathrm{d}$-orbital populations roughly agree with the occupation order of the d-electron levels for the square planar complexes. The total d-population is about 9 and electron density in $4 \mathrm{~s}$ is about 0.5 . It may be pointed out that the electron density in $3 \mathrm{~d}$ orbital depends on the strength of the probe ligand. In complexes 6 and 8 the $\mathrm{d}_{x y}$ orbital has occupancy of 1.5 while in 2,3 , and 7 the population in $\mathrm{d}_{x^{2}-y^{2}}$ is about 1.5. This establishes the interaction between these orbitals of metal atom and the orbitals of donor atom of the ligands. It may be suggested here that the pair of electrons from the ligand is transferred mainly to $\mathrm{d}_{x y}$ and $\mathrm{d}_{x^{2}-y^{2}}$ orbitals. This confirms that these complexes are in square planar geometry.
3.3. Wiberg Bond Indices. The Wiberg bond indices (WBI) were calculated for all complexes 1-9. These values are given in Table 4. The WBI of the interaction between $\mathrm{Cu}$ (III) and methyl ligand in complex $1(\mathrm{Cu}(\mathrm{III})-\mathrm{Me})$ is found to be 0.34 and in complexes 8 and 9 , the WBI of $\mathrm{Cu}(\mathrm{III})$ $\mathrm{L}$ interactions are found to be 0.29 and 0.25 , respectively. Thus the interaction between $\mathrm{Cu}(\mathrm{III})$ and probe ligands is weaker in these complexes than $\mathrm{Cu}(\mathrm{III})$-Me interaction in TMC complex. In the complexes, $\left[\mathrm{Cu}\left(\mathrm{NH}_{2}\right)\left(\mathrm{CH}_{3}\right)_{3}\right]^{-1}$ (5) cis $\left[\mathrm{Cu}\left(\mathrm{NH}_{2}\right)_{2}\left(\mathrm{CH}_{3}\right)_{2}\right]^{-1}(\mathbf{6})$, WBI of the interaction between $\mathrm{Cu}(\mathrm{III})$ and probe ligands are less than 0.34 indicating the weaker interaction between the metal ion and probe ligands. However, $\mathrm{Cu}(\mathrm{III})-\mathrm{Me}$ interactions are stronger in these two complexes as evident from their higher WBI values. The metal-ligand interactions are stronger when the probe ligands are $\mathrm{N}^{3-}$ and $\mathrm{NH}^{2-}$. The data in Table 4 also indicate that $\mathrm{Cu}(\mathrm{III})$-Me interactions are influenced by the nature of the probe ligand.

3.4. Chemical Hardness ( $\eta$ ). As the $\mathrm{Cu}(\mathrm{III})$-alkyl complexes have been used for the effective $\mathrm{C}-\mathrm{C}$ bond formation at low 
TABLE 2: Computed NPA charge of copper (III) complexes 1-9.

\begin{tabular}{|c|c|c|c|c|c|}
\hline Complexes & & $\mathrm{Cu}$ & $\mathrm{L}$ & $\mathrm{Me}_{\text {cis }}$ & $\mathrm{Me}_{\text {trans }}$ \\
\hline$\left[\mathrm{Cu}\left(\mathrm{CH}_{3}\right)_{4}\right]^{-1}$ & (1) & 0.99 & & & \\
\hline$\left[\mathrm{CuN}\left(\mathrm{CH}_{3}\right)_{3}\right]^{3-}$ & (2) & -0.36 & $-1.06(\mathrm{~N})$ & -1.13 & -1.02 \\
\hline$\left[\mathrm{Cu}(\mathrm{NH})\left(\mathrm{CH}_{3}\right)_{3}\right]^{2-}$ & (3) & 0.68 & $-1.30(\mathrm{NH})$ & -1.08 & -1.10 \\
\hline $\operatorname{trans}\left[\mathrm{Cu}(\mathrm{NH})_{2}\left(\mathrm{CH}_{3}\right)_{2}\right]^{3-}$ & $(4)$ & -0.03 & $-1.20(\mathrm{NH})$ & -1.04 & \\
\hline$\left[\mathrm{Cu}\left(\mathrm{NH}_{2}\right)\left(\mathrm{CH}_{3}\right)_{3}\right]^{-1}$ & (5) & 1.03 & $-1.31\left(\mathrm{NH}_{2}\right)$ & -1.05 & -0.99 \\
\hline $\operatorname{cis}\left[\mathrm{Cu}\left(\mathrm{NH}_{2}\right)_{2}\left(\mathrm{CH}_{3}\right)_{2}\right]^{-1}$ & $(6)$ & 1.07 & $-1.31\left(\mathrm{NH}_{2}\right)$ & -0.98 & -0.98 \\
\hline $\operatorname{trans}\left[\mathrm{Cu}\left(\mathrm{NH}_{2}\right)_{2}\left(\mathrm{CH}_{3}\right)_{2}\right]^{-1}$ & $(7)$ & 1.10 & $-1.26\left(\mathrm{NH}_{2}\right)$ & -1.04 & -1.04 \\
\hline$\left[\mathrm{Cu}\left(\mathrm{NHCH}_{2}-\mathrm{CH}_{2} \mathrm{NH}\right)\left(\mathrm{CH}_{3}\right)_{2}\right]^{-1}$ & $(8)$ & 1.08 & $-1.07(\mathrm{~N})$ & -1.01 & \\
\hline$\left[\mathrm{Cu}(\mathrm{NH})_{2} \mathrm{C}_{6} \mathrm{H}_{4}\left(\mathrm{CH}_{3}\right)_{2}\right]^{-1}$ & $(9)$ & 1.14 & $-1.01(\mathrm{~N})$ & -0.96 & \\
\hline
\end{tabular}

TABLE 3: Calculated natural atomic orbital occupancy of copper ion in complexes 1-9.

\begin{tabular}{|c|c|c|c|c|c|c|c|}
\hline \multirow{2}{*}{ Complexes } & & \multicolumn{6}{|c|}{ Occupancy of $\mathrm{Cu}(3 \mathrm{~d}, 4 \mathrm{~s})$} \\
\hline & & $\mathrm{d}_{x y}$ & $\mathrm{~d}_{x z}$ & $\mathrm{~d}_{y z}$ & $\mathrm{~d}_{z^{2}}$ & $\mathrm{~d}_{x^{2}-y^{2}}$ & $s$ \\
\hline$\left[\mathrm{Cu}\left(\mathrm{CH}_{3}\right)_{4}\right]^{-1}$ & (1) & 1.58 & 1.99 & 1.99 & 1.97 & 1.99 & 0.44 \\
\hline$\left[\mathrm{CuN}\left(\mathrm{CH}_{3}\right)_{3}\right]^{3-}$ & (2) & 1.98 & 1.99 & 1.99 & 1.97 & 1.58 & 0.42 \\
\hline$\left[\mathrm{Cu}(\mathrm{NH})\left(\mathrm{CH}_{3}\right)_{3}\right]^{2-}$ & (3) & 1.95 & 1.99 & 1.99 & 1.97 & 1.60 & 0.42 \\
\hline $\operatorname{trans}\left[\mathrm{Cu}(\mathrm{NH})_{2}\left(\mathrm{CH}_{3}\right)_{2}\right]^{3-}$ & (4) & 1.98 & 1.99 & 1.98 & 1.96 & 1.55 & 0.41 \\
\hline$\left[\mathrm{Cu}\left(\mathrm{NH}_{2}\right)\left(\mathrm{CH}_{3}\right)_{3}\right]^{-1}$ & (5) & 1.99 & 1.99 & 1.99 & 1.97 & 1.54 & 0.41 \\
\hline $\operatorname{cis}\left[\mathrm{Cu}\left(\mathrm{NH}_{2}\right)_{2}\left(\mathrm{CH}_{3}\right)_{2}\right]^{-1}$ & (6) & 1.51 & 1.99 & 1.99 & 1.97 & 1.99 & 0.40 \\
\hline $\operatorname{trans}\left[\mathrm{Cu}\left(\mathrm{NH}_{2}\right)_{2}\left(\mathrm{CH}_{3}\right)_{2}\right]^{-1}$ & (7) & 1.96 & 1.99 & 1.99 & 1.97 & 1.52 & 0.40 \\
\hline$\left[\mathrm{Cu}\left(\mathrm{NHCH}_{2}-\mathrm{CH}_{2} \mathrm{NH}\right)\left(\mathrm{CH}_{3}\right)_{2}\right]^{-1}$ & (8) & 1.51 & 1.99 & 1.99 & 1.97 & 1.99 & 0.40 \\
\hline$\left[\mathrm{Cu}(\mathrm{NH})_{2} \mathrm{C}_{6} \mathrm{H}_{4}\left(\mathrm{CH}_{3}\right)_{2}\right]^{-1}$ & (9) & 1.99 & 1.99 & 1.47 & 1.98 & 1.98 & 0.39 \\
\hline
\end{tabular}

temperature, several $\mathrm{Cu}(\mathrm{III})$-alkyl intermediates have also been characterized by Rapid Injection NMR technique [6-11] and theoretical studies have been carried out to understand the stability and reactivity of $\mathrm{Cu}(\mathrm{III})$-alkyl complexes in terms of chemical hardness $[6,8,11,19]$. The experimental observations so far made in these studies indicate clearly that the $\mathrm{Cu}(\mathrm{III})$-alkyl complexes are not stable enough to isolate at room temperature and characterize. In order to understand more about the stability of $\mathrm{Cu}$ (III)-alkyl complexes, we computed the total chemical hardness $(\eta)$ of complexes 1-9 using the energies of HOMO and LUMO. The $\eta$ value can be from the energy values using the equation [39], $\eta=1 / 2\left(E_{\text {LUMO }}-\right.$ $\left.E_{\text {HOMO }}\right)$. The FMO diagrams for complexes 1-9 are depicted in Figure 2. The calculated chemical hardness for complexes 1-9 is listed in Table 5. According to Pearson's principle [40], complexes having higher chemical hardness will have more stability than complexes with smaller $\eta$ values. It is evident from the data in Table 5 that complexes 6-9 have comparable hardness and chemical hardness of these complexes is comparable to that of tetramethylcuprate(III) complex. Thus, these four complexes may have stability comparable to that of complex 1. Relatively smaller chemical hardness values are obtained for complexes 2-5 and hence these four complexes are expected to be less stable than complex 1.

3.5. Energy Decomposition Analysis. Energy decomposition analysis (EDA) is a useful tool to understand the nature of $\mathrm{Cu}$ (III)-L ( $\mathrm{L}=$ probe ligand) and $\mathrm{Cu}(\mathrm{III})$-alkyl bond and also to estimate the intermolecular interaction energies of metal-ligand systems. Also the separation into the different contributions to this interaction energy gives insight into the nature of the bond. Energy decomposition analysis (EDA) was performed for complexes $1-9$ and the results obtained are given in Table 6.

The Pauli repulsive force $\left(\Delta E_{\text {pauli }}\right)$ is slightly more than the electrostatic interaction $\left(\Delta E_{\text {elstat }}\right)$ for complexes 5-9 in which the probe ligands are amido, ethylene diamido, and aryl diamido. Further, in these complexes the electrostatic interaction energy is greater than the orbital overlap energy. These results indicate that the $\mathrm{Cu}$ (III)-L interaction is more of ionic in nature in these four complexes. The ionic nature decreases in the order $9>8>7>6$. Baskaran et al. found that interaction of nitrogen containing probe ligands with $\mathrm{Cu}$ (III) is ionic in nature [41]. In complexes $2-4, \Delta E_{\text {pauli values for }}$ $\mathrm{Cu}(\mathrm{III})-\mathrm{L}$ interaction are greater than $\Delta E_{\text {elstat }}$ values. It may be pointed out that orbital interaction energy values are greater than electrostatic contribution suggesting that $\mathrm{M}-\mathrm{L}$ interaction is less ionic in these three complexes than in complexes 5-9.

EDA analysis can be used to consider the interaction of $\mathrm{Me}_{\text {cis }}$ with the $\mathrm{Cu}$ (III) center. The energy decomposition of $\mathrm{Cu}(\mathrm{III})-\mathrm{Me}_{\mathrm{cis}}$ bond of complexes 2, 3, and 5 containing $\mathrm{N}$ ligands is shown in Table 6 and Figure 3(a). The $\Delta E_{\text {pauli }}$ repulsive force is calculated to be more than $\Delta E_{\text {elstat }}$ for $\mathrm{Cu}$ (III) $-\mathrm{Me}_{\text {cis }}$ bond in the three complexes. However, the difference between $\Delta E_{\text {pauli }}$ and $\Delta E_{\text {elstat }}$ is more for the complexes containing $\mathrm{N}^{-3}$ and $\mathrm{NH}^{-2}$ ligands than amido ligand. Further, $\Delta E_{\text {orb }}$ for the $\mathrm{Cu}(\mathrm{III})-\mathrm{Me}_{\text {cis }}$ bond is calculated to be less than 
TABLE 4: Calculated Wiberg bond indices of different bonds in complexes 1-9.

\begin{tabular}{|c|c|c|c|c|}
\hline \multirow{2}{*}{ Complexes } & & \multicolumn{3}{|c|}{ WBI } \\
\hline & & $\mathrm{Cu}-\mathrm{L}$ & $\mathrm{Cu}-\mathrm{Me}_{\mathrm{cis}}$ & $\mathrm{Cu}-\mathrm{Me}_{\text {trans }}$ \\
\hline$\left[\mathrm{Cu}\left(\mathrm{CH}_{3}\right)_{4}\right]^{-1}$ & $(\mathbf{1})$ & & 0.34 & \\
\hline$\left[\mathrm{CuN}\left(\mathrm{CH}_{3}\right)_{3}\right]^{3-}$ & (2) & $1.46(\mathrm{~N})$ & 0.42 & 0.34 \\
\hline$\left[\mathrm{Cu}(\mathrm{NH})\left(\mathrm{CH}_{3}\right)_{3}\right]^{2-}$ & (3) & $0.90(\mathrm{NH})$ & $\begin{array}{l}0.39 \\
0.35\end{array}$ & 0.34 \\
\hline $\operatorname{trans}\left[\mathrm{Cu}(\mathrm{NH})_{2}\left(\mathrm{CH}_{3}\right)_{2}\right]^{3-}$ & (4) & $1.03(\mathrm{NH})$ & $\begin{array}{l}0.47 \\
0.42\end{array}$ & \\
\hline$\left[\mathrm{Cu}\left(\mathrm{NH}_{2}\right)\left(\mathrm{CH}_{3}\right)_{3}\right]^{-1}$ & (5) & $0.31\left(\mathrm{NH}_{2}\right)$ & 0.34 & 0.40 \\
\hline $\operatorname{cis}\left[\mathrm{Cu}\left(\mathrm{NH}_{2}\right)_{2}\left(\mathrm{CH}_{3}\right)_{2}\right]^{-1}$ & $(6)$ & $0.31\left(\mathrm{NH}_{2}\right)$ & 0.41 & 0.41 \\
\hline $\operatorname{trans}\left[\mathrm{Cu}\left(\mathrm{NH}_{2}\right)_{2}\left(\mathrm{CH}_{3}\right)_{2}\right]^{-1}$ & (7) & $0.36\left(\mathrm{NH}_{2}\right)$ & 0.35 & 0.35 \\
\hline$\left[\mathrm{Cu}\left(\mathrm{NHCH}_{2}-\mathrm{CH}_{2} \mathrm{NH}\right)\left(\mathrm{CH}_{3}\right)_{2}\right]^{-1}$ & (8) & $0.29(\mathrm{NH})$ & 0.39 & 0.39 \\
\hline$\left[\mathrm{Cu}(\mathrm{NH})_{2} \mathrm{C}_{6} \mathrm{H}_{4}\left(\mathrm{CH}_{3}\right)_{2}\right]^{-1}$ & (9) & $0.25(\mathrm{NH})$ & 0.44 & 0.44 \\
\hline
\end{tabular}

TABLE 5: HOMO, LUMO energies and chemical hardness of complexes 1-9.

\begin{tabular}{lccccc}
\hline Serial number & Complexes & & HOMO (hartree) & LUMO (hartree) & $\eta=\left(E_{\mathrm{LUMO}}-E_{\mathrm{HOMO}}\right) / 2 \mathrm{eV}$ \\
\hline 1 & {$\left[\mathrm{Cu}\left(\mathrm{CH}_{3}\right)_{4}\right]^{-1}$} & $(\mathbf{1})$ & -0.02871 & 0.14268 & 2.33 \\
2 & {$\left[\mathrm{CuN}\left(\mathrm{CH}_{3}\right)_{3}\right]^{3-}$} & $(\mathbf{2})$ & 0.30437 & 0.35232 & 0.65 \\
3 & {$\left[\mathrm{Cu}(\mathrm{NH})\left(\mathrm{CH}_{3}\right)_{3}\right]^{2-}$} & $(\mathbf{3})$ & 0.18447 & 0.25194 & 0.91 \\
4 & $\operatorname{trans}\left[\mathrm{Cu}(\mathrm{NH})_{2}\left(\mathrm{CH}_{3}\right)_{2}\right]^{3-}$ & $(\mathbf{4})$ & 0.29798 & 0.35727 & 0.81 \\
5 & {$\left[\mathrm{Cu}\left(\mathrm{NH}_{2}\right)\left(\mathrm{CH}_{3}\right)_{3}\right]^{-1}$} & $(\mathbf{5})$ & -0.01870 & 0.13911 & 1.07 \\
6 & $\operatorname{cis}\left[\mathrm{Cu}\left(\mathrm{NH}_{2}\right)_{2}\left(\mathrm{CH}_{3}\right)_{2}\right]^{-1}$ & $(\mathbf{6})$ & -0.01083 & 0.12937 & 1.90 \\
7 & $\operatorname{trans}\left[\mathrm{Cu}\left(\mathrm{NH}_{2}\right)_{2}\left(\mathrm{CH}_{3}\right)_{2}\right]^{-1}$ & $(\mathbf{7})$ & -0.02691 & 0.12681 & 2.09 \\
8 & {$\left[\mathrm{Cu}\left(\mathrm{NHCH}{ }_{2}-\mathrm{CH}_{2} \mathrm{NH}_{(}\left(\mathrm{CH}_{3}\right)_{2}\right]^{-1}\right.$} & $(\mathbf{8})$ & 0.27318 & 0.50635 & 3.17 \\
9 & {$\left[\mathrm{Cu}(\mathrm{NH})_{2} \mathrm{C}_{6} \mathrm{H}_{4}\left(\mathrm{CH}_{3}\right)_{2}\right]^{-1}$} & $(\mathbf{9})$ & 0.22365 & 0.37096 & 2.04 \\
\hline
\end{tabular}

TABLE 6: Energy decomposition analysis of copper III complexes with nitrogen.

\begin{tabular}{|c|c|c|c|c|c|c|c|c|}
\hline Serial number & Complexes & & Fragment (A) & Fragment (B) & $\begin{array}{c}\Delta E_{\text {Pauli }} \\
\mathrm{kcal} \mathrm{mol}^{-1}\end{array}$ & $\Delta E_{\text {elstat }}$ & $\Delta E_{\text {orb }}$ & $\Delta E_{\mathrm{int}}$ \\
\hline 1 & {$\left[\mathrm{Cu}\left(\mathrm{CH}_{3}\right)_{4}\right]^{-1}$} & (1) & {$\left[\mathrm{Cu}\left(\mathrm{CH}_{3}\right)_{3}\right]$} & {$\left[\mathrm{CH}_{3}\right]^{-1}$} & 173.51 & -183.65 & -72.94 & -83.08 \\
\hline \multirow{3}{*}{2} & \multirow{3}{*}[\mathrm{CuN}(\mathrm{CH}_{3})_{3}]{$^{3-}$} & \multirow{3}{*}{$(2)$} & {$\left[\mathrm{Cu}\left(\mathrm{CH}_{3}\right)_{3}\right]$} & $\mathrm{N}^{3-}$ & 392.19 & -318.61 & -370.89 & -397.31 \\
\hline & & & {$\left[\mathrm{CuN}\left(\mathrm{CH}_{3}\right)_{2}\right]^{-2}$} & $\operatorname{trans}\left[\mathrm{CH}_{3}\right]^{-1}$ & 253.46 & -8.37 & -144.74 & 100.35 \\
\hline & & & {$\left[\mathrm{CuN}\left(\mathrm{CH}_{3}\right)_{2}\right]^{-2}$} & $\operatorname{cis}\left[\mathrm{CH}_{3}\right]^{-1}$ & 262.20 & -11.67 & -61.07 & 189.46 \\
\hline \multirow{3}{*}{3} & \multirow{3}{*}[\mathrm{Cu}(\mathrm{NH})(\mathrm{CH}_{3})_{3}]{$^{2-}$} & \multirow{3}{*}{ (3) } & {$\left[\mathrm{Cu}\left(\mathrm{CH}_{3}\right)_{3}\right]$} & $\mathrm{NH}^{-2}$ & 200.43 & -179.02 & -248.95 & -227.54 \\
\hline & & & {$\left[\mathrm{Cu}(\mathrm{NH})\left(\mathrm{CH}_{3}\right)_{2}\right]^{-1}$} & $\operatorname{cis}\left[\mathrm{CH}_{3}\right]^{-1}$ & 179.29 & -76.42 & -67.28 & 35.58 \\
\hline & & & {$\left[\mathrm{Cu}(\mathrm{NH})\left(\mathrm{CH}_{3}\right)_{2}\right]^{-1}$} & $\operatorname{trans}\left[\mathrm{CH}_{3}\right]^{-1}$ & 166.34 & -76.78 & -57.20 & 32.35 \\
\hline \multirow{2}{*}{4} & \multirow{2}{*}{$\operatorname{trans}\left[\mathrm{Cu}(\mathrm{NH})_{2}\left(\mathrm{CH}_{3}\right)_{2}\right]^{3-}$} & \multirow[t]{2}{*}{ (4) } & $\operatorname{trans}\left[\mathrm{Cu}(\mathrm{NH})\left(\mathrm{CH}_{3}\right)_{2}\right]^{-1}$ & {$[\mathrm{NH}]^{-2}$} & 207.11 & -12.67 & -308.82 & -114.38 \\
\hline & & & $\operatorname{trans}\left[\mathrm{Cu}(\mathrm{NH})_{2}\left(\mathrm{CH}_{3}\right)\right]^{2-}$ & {$\left[\mathrm{CH}_{3}\right]^{-1}$} & 227.47 & 4.24 & -91.84 & 139.87 \\
\hline \multirow{3}{*}{5} & \multirow{3}{*}[\mathrm{Cu}(\mathrm{NH}_{2})(\mathrm{CH}_{3})_{3}]{$^{-1}$} & \multirow{3}{*}{$(5)$} & {$\left[\mathrm{Cu}\left(\mathrm{CH}_{3}\right)_{3}\right]$} & {$\left[\mathrm{NH}_{2}\right]^{-1}$} & 128.23 & -142.92 & -66.43 & -81.11 \\
\hline & & & {$\left[\mathrm{Cu}\left(\mathrm{NH}_{2}\right)\left(\mathrm{CH}_{3}\right)_{2}\right]$} & $\operatorname{cis}\left[\mathrm{CH}_{3}\right]^{-1}$ & 175.05 & -183.85 & -73.79 & -82.60 \\
\hline & & & {$\left[\mathrm{Cu}\left(\mathrm{NH}_{2}\right)\left(\mathrm{CH}_{3}\right)_{2}\right]$} & $\operatorname{trans}\left[\mathrm{CH}_{3}\right]^{-1}$ & 179.57 & -197.60 & -81.92 & -99.95 \\
\hline \multirow{2}{*}{6} & \multirow{2}{*}{$\operatorname{cis}\left[\mathrm{Cu}\left(\mathrm{NH}_{2}\right)_{2}\left(\mathrm{CH}_{3}\right)_{2}\right]^{-1}$} & \multirow{2}{*}{$(6)$} & {$\left[\mathrm{Cu}\left(\mathrm{NH}_{2}\right)\left(\mathrm{CH}_{3}\right)_{2}\right]$} & {$\left[\mathrm{NH}_{2}\right]^{-1}$} & 124.81 & -140.06 & -65.21 & -80.46 \\
\hline & & & {$\left[\mathrm{Cu}\left(\mathrm{NH}_{2}\right)_{2}\left(\mathrm{CH}_{3}\right)\right]$} & {$\left[\mathrm{CH}_{3}\right]^{-1}$} & 192.01 & -198.92 & -87.41 & -94.32 \\
\hline \multirow{2}{*}{7} & \multirow{2}{*}{$\operatorname{trans}\left[\mathrm{Cu}\left(\mathrm{NH}_{2}\right)_{2}\left(\mathrm{CH}_{3}\right)_{2}\right]^{-1}$} & \multirow{2}{*}{ (7) } & {$\left[\mathrm{Cu}\left(\mathrm{NH}_{2}\right)\left(\mathrm{CH}_{3}\right)_{2}\right]$} & {$\left[\mathrm{NH}_{2}\right]^{-1}$} & 130.56 & -152.50 & -72.74 & -94.68 \\
\hline & & & {$\left[\mathrm{Cu}\left(\mathrm{NH}_{2}\right)_{2}\left(\mathrm{CH}_{3}\right)\right]$} & {$\left[\mathrm{CH}_{3}\right]^{-1}$} & 177.09 & -185.29 & -75.05 & -83.25 \\
\hline 8 & {$\left[\mathrm{Cu}\left(\mathrm{NHCH}_{2}-\mathrm{CH}_{2} \mathrm{NH}\right)\left(\mathrm{CH}_{3}\right)_{2}\right]^{-1}$} & $(8)$ & {$\left[\mathrm{Cu}\left(\mathrm{NHCH}_{2}-\mathrm{H}_{2} \mathrm{NH}\right) \mathrm{CH}_{3}\right]$} & {$\left[\mathrm{CH}_{3}\right]^{-1}$} & 184.15 & -196.68 & -83.24 & -95.77 \\
\hline 9 & {$\left[\mathrm{Cu}(\mathrm{NH})_{2} \mathrm{C}_{6} \mathrm{H}_{4}\left(\mathrm{CH}_{3}\right)_{2}\right]^{-1}$} & $(9)$ & {$\left[\mathrm{Cu}(\mathrm{NH})_{2} \mathrm{C}_{6} \mathrm{H}_{4}\left(\mathrm{CH}_{3}\right)\right]$} & {$\left[\mathrm{CH}_{3}\right]^{-1}$} & 211.58 & -231.41 & -110.68 & -130.51 \\
\hline
\end{tabular}



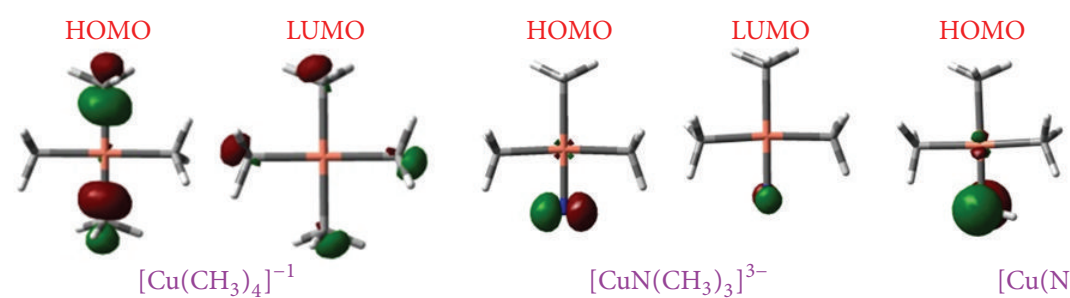

\section{LUMO}
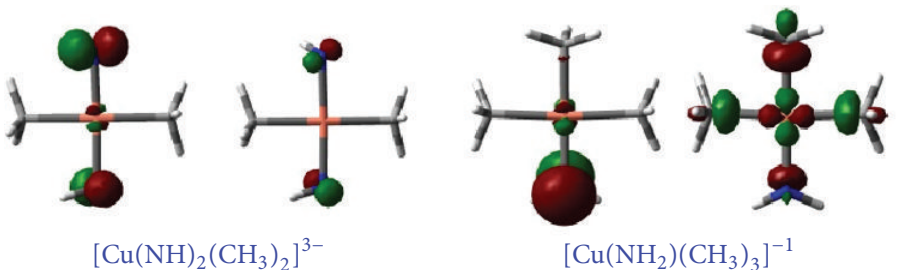

$\left[\mathrm{Cu}(\mathrm{NH})\left(\mathrm{CH}_{3}\right)_{3}\right]^{2-}$

$\left[\mathrm{Cu}(\mathrm{NH})_{2}\left(\mathrm{CH}_{3}\right)_{2}\right]^{3-}$
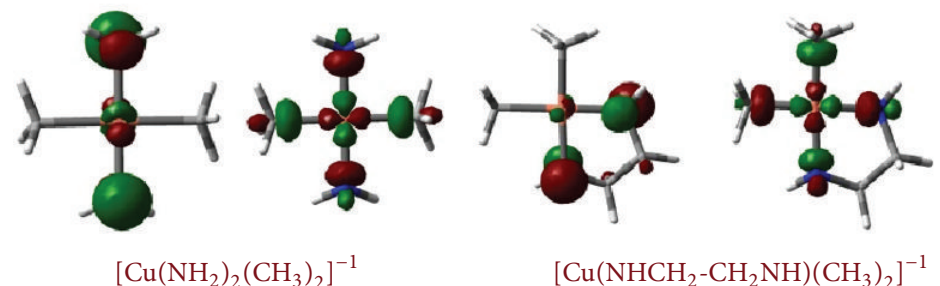

$\left[\mathrm{Cu}\left(\mathrm{NHCH}_{2}-\mathrm{CH}_{2} \mathrm{NH}\right)\left(\mathrm{CH}_{3}\right)_{2}\right]^{-1}$

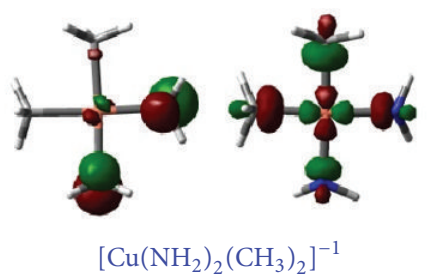

FIGURE 2: FMO of copper(III) complexes (1-9) with methyl and nitrogen donor ligands.

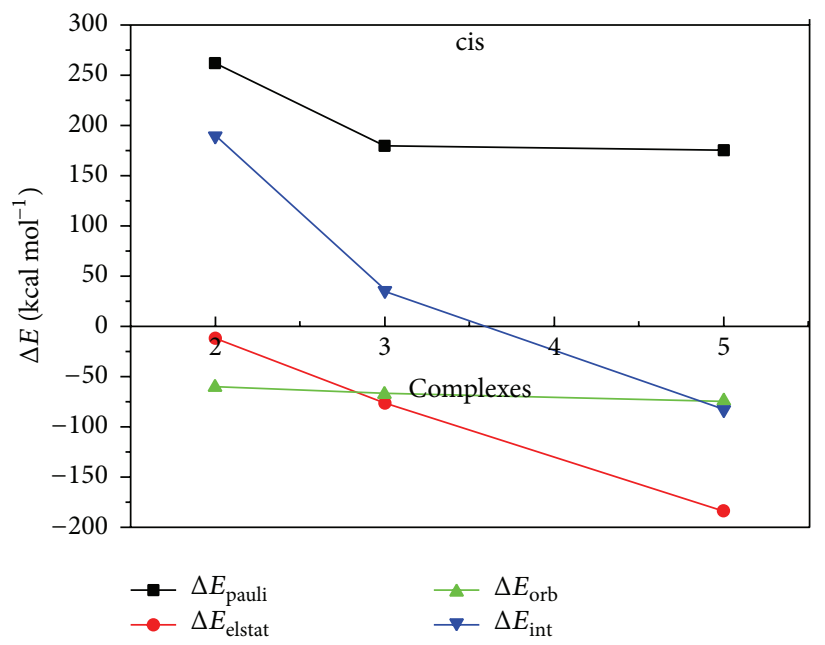

(a)

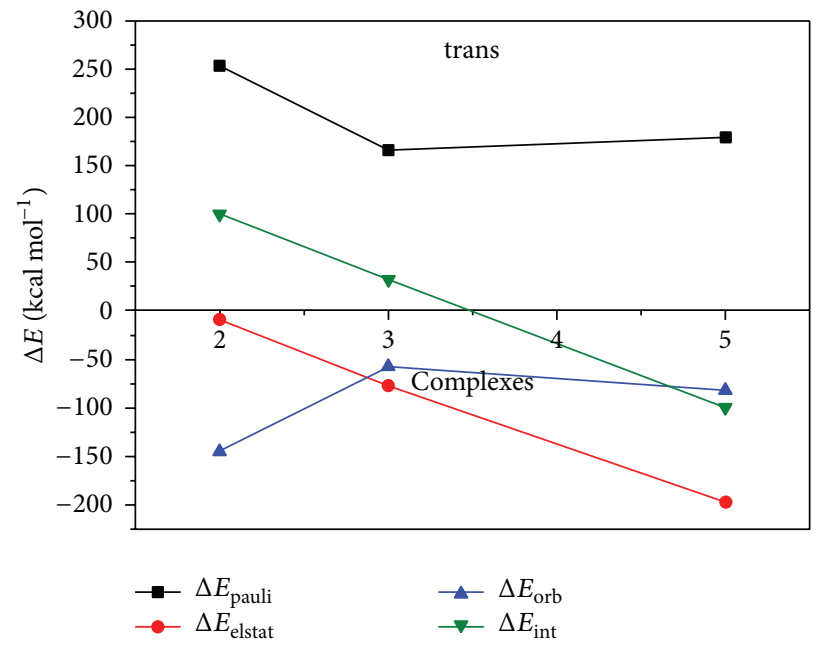

(b)

FIGURE 3: EDA for metal center, cis- and trans-methyl group for the three complexes 2, 3, and 5.

$\Delta E_{\text {elstat }}$ for complexes 3 and 5 and reveals that in these two complexes $\mathrm{M}-\mathrm{L}_{\text {cis }}$ is more ionic than in complex 2 . In the case of other complexes $(4,6-9)$ Pauli repulsive forces are less and $\Delta E_{\text {orb }}$ values are less than $\Delta E_{\text {elstat }}$ values. Thus, $\mathrm{Cu}(\mathrm{III})-\mathrm{Me}$ interaction is more ionic in these four complexes. The energy decomposition of the $\mathrm{Cu}(\mathrm{III})-\mathrm{Me}_{\text {trans }}$ bond of complexes 2, 3, and 5 is shown in Figure 3(b). It is found that the computed $\Delta E_{\text {pauli }}$ is calculated to be less than $\Delta E_{\text {elstat }}$ for complex (5) containing amido ligand as probe ligand indicating that in this complex $\mathrm{Cu}-\mathrm{Me}_{\text {trans }}$ interaction is more ionic which is similar to the trend observed for the $\mathrm{Cu}(\mathrm{III})-\mathrm{Me}_{\text {cis }}$ bond.
However, in the case of complexes 2 and 3 the interaction is ionic but less ionic than in complex 5 .

3.6. Free Energy of the Ligand Substitution Reactions. Free energy changes of the nitrogen donor ligand substitution reactions on the $\mathrm{Cu}$ (III)-methyl complex are calculated for the eight reactions.

Figure 4 depicts the free energy changes for the seven ligand substitution reactions (except substitution by $\mathrm{N}^{-3}$ ligand). $\Delta G$ for the substitution of methyl group by $\mathrm{N}^{-3}$ 


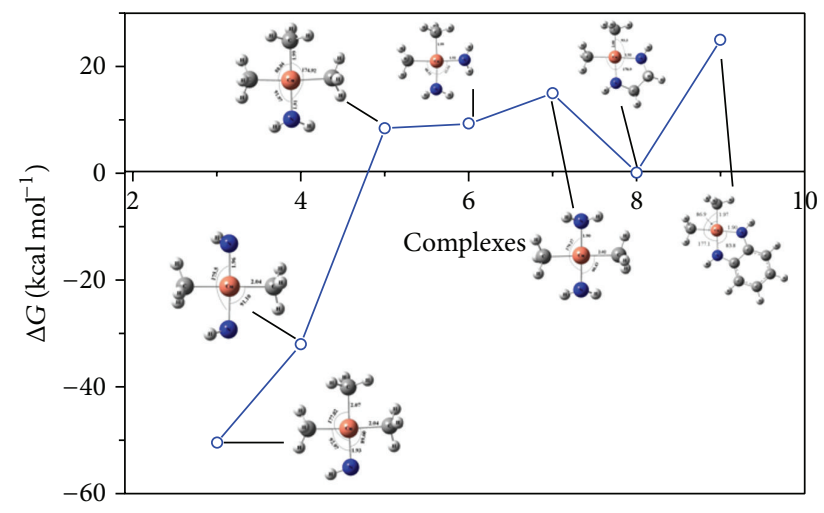

FIGURE 4: Free energy changes of ligand substitution reactions on the $\mathrm{Cu}(\mathrm{III})$-methyl complexes with nitrogen donor ligands.

probe ligandis- $496.47 \mathrm{kcal} \mathrm{mol}^{-1}$ at $298 \mathrm{~K}$ in THF solvent. Thus the reaction is thermodynamically feasible. Similarly the values of $\Delta G$ for the formation of complexes 3 and 4 from TMC are also negative and these reactions are also feasible thermodynamically at the specified experimental conditions. However, the formation of complexes 4-9 from TMC has positive free energy and hence it may be inferred that these substitution reactions involving amido, ethylene diamido, and aryl diamido probe ligands are thermodynamically not feasible under the specified conditions.

\section{Conclusions}

DFT studies were performed on eight ligand substitution reactions of tetramethylcuprate(III) (TMC) complex with five different probe ligands containing nitrogen as donor atom. The geometry optimization of the possible nine model systems and the frequency calculations were carried out using LANL2DZ basis set and no imaginary frequencies were obtained. The bond parameters of optimized model systems of $\mathrm{Cu}(\mathrm{III})$ complexes are reported and discussed. The change in the $\mathrm{Cu}$ (III)-C bond distance in TNC due to substitution by probe ligands is studied. Natural population analysis (NPA) has been carried out for these complexes to establish the charge on copper center in these complexes. A detailed population analysis of valence orbitals of copper complexes supports the existence of $\mathrm{d}^{8}$ configuration for metal in these complexes and there is evidence for the transmission of electrons from the nitrogen donor atom to $\mathrm{d}_{x y}, \mathrm{~d}_{x^{2}-y^{2}}$, and $4 \mathrm{~s}$ orbitals. There is evidence for the interaction between these orbitals $\left(\mathrm{d}_{x^{2}-y^{2}}\right.$ and $\left.\mathrm{d}_{x y}\right)$ of metal atom and the orbitals of donor atom of the ligands. It may be suggested here that the pair of electrons from the ligand is transferred mainly to $\mathrm{d}_{x y}$ and $\mathrm{d}_{x^{2}-y^{2}}$ orbitals. This confirms that these complexes are in square planar geometry. It may be pointed out that the electron density in $3 \mathrm{~d}$ orbital depends on the strength of the probe ligand. Bond order calculations have been performed for all the complexes to ascertain the interaction between $\mathrm{Cu}$ (III) and the ligand. The stability is determined from the computed chemical hardness of these complexes. Energy decomposition analysis has been carried out for all the complexes chosen in the theoretical study to understand the nature of $\mathrm{Cu}$ (III)- $\mathrm{L}$ ( $\mathrm{L}=\mathrm{N}$ donors) and $\mathrm{Cu}(\mathrm{III})-\mathrm{Me}$ bonds in different complexes. Thermodynamic feasibility of these reactions is investigated in terms of free energy changes of the reactions.

\section{Competing Interests}

The authors declare that they have no competing interests.

\section{Acknowledgments}

The authors thank the managements of Guru Nanak College, Chennai, and The New College, Chennai, for the facilities provided and encouragements shown towards this work.

\section{References}

[1] N. Krause, Modern Organocopper Chemistry, Wiley-VCH, Weinheim, Germany, 2002.

[2] R. J. K. Taylor, Organocopper Reagents: A Practical Approach, Oxford University Press, Oxford, UK, 1994.

[3] B. H. Lipshutz and S. Sengupta, "Organocopper reagents: substitution, conjugate addition, carbo/metallocupration, and other reactions," Organic Reactions, vol. 41, pp. 135-631, 1992.

[4] G. H. Posner, "Substitution reactions using organocopper reagents," Organic Reactions, vol. 22, pp. 253-400, 1975.

[5] G. H. Posner, "Conjugate addition reactions of copper reagents," Organic Reactions, vol. 19, pp. 1-113, 1972.

[6] S. H. Bertz, S. Cope, M. Murphy, C. A. Ogle, and B. J. Taylor, "Rapid injection NMR in mechanistic organocopper chemistry. Preparation of the elusive copper(III) intermediate," Journal of the American Chemical Society, vol. 129, no. 23, pp. 7208-7209, 2007.

[7] S. H. Bertz, S. Cope, D. Dorton, M. Murphy, and C. A. Ogle, "Organocuprate cross-coupling: the central role of the copper(III) intermediate and the importance of the copper(I) precursor," Angewandte Chemie-International Edition, vol. 46, no. 37, pp. 7082-7085, 2007.

[8] T. Gärtner, W. Henze, and R. M. Gschwind, "NMR-detection of $\mathrm{Cu}$ (III) intermediates in substitution reactions of alkyl halides with Gilman cuprates," Journal of the American Chemical Society, vol. 129, no. 37, pp. 11362-11363, 2007.

[9] D. Naumann, T. Roy, K.-F. Tebbe, and W. Crump, "Synthesis and structure of surprisingly stable tetrakis(trifluoromethyl)cuprate(III) salts," Angewandte Chemie-International Edition, vol. 32, no. 10, pp. 1482-1483, 1993.

[10] R. Eujen, B. Hoge, and D. J. Brauer, "Synthesis and properties of donor-free bis(difluoromethyl) cadmium, $(\mathrm{CF} 2 \mathrm{H}) 2 \mathrm{Cd}$ NMR spectroscopic detection and structure of tetrakis(difluoromethyl) cuprate(III) and related compounds," Journal of Organometallic Chemistry, vol. 519, no. 1-2, pp. 7-20, 1996.

[11] E. R. Bartholomew, S. H. Bertz, S. Cope, D. C. Dorton, M. Murphy, and C. A. Ogle, "Neutral organocopper(III) complexes," Chemical Communications, no. 10, pp. 1176-1177, 2008.

[12] H. Hu and J. P. Snyder, "Organocuprate conjugate addition: the square-planar ' $\mathrm{Cu}$ ' intermediate," Journal of the American Chemical Society, vol. 129, no. 23, pp. 7210-7211, 2007.

[13] J. P. Snyder, "Mechanism of lithium cuprate conjugate addition: neutral tetracoordinate CuI cuprates as essential intermediates," 
Journal of the American Chemical Society, vol. 117, no. 44, pp. 11025-11026, 1995.

[14] J. P. Snyder, "Elusiveness of $\mathrm{Cu}^{\mathrm{III}}$ complexation; preference for trifluoromethyl oxidation in the formation of $\left[\mathrm{C}^{\mathrm{I}}\left(\mathrm{CF}_{3}\right)_{4}\right]^{-}$salts," Angewandte Chemie, vol. 34, no. 1, pp. 80-81, 1995.

[15] S. Mori, E. Nakamura, and K. Morokuma, "Mechanism of $\mathrm{S}_{\mathrm{N}} 2$ alkylation reactions of lithium organocuprate clusters with alkyl halides and epoxides. Solvent effects, BF3 effects, and transdiaxial epoxide opening," Journal of the American Chemical Society, vol. 122, no. 30, pp. 7294-7307, 2000.

[16] A. E. Dorigo, J. Wanner, and P. V. R. Schleyer, "Computational evidence for the existence of $\mathrm{Cu}^{\mathrm{III}}$ intermediates in addition and substitution reactions with dialkylcuprates," Angewandte Chemie-International Edition, vol. 34, no. 4, pp. 476-478, 1995.

[17] E. R. Bartholomew, S. H. Bertz, S. K. Cope, M. D. Murphy, C. A. Ogle, and A. A. Thomas, "Serendipity strikes again-efficient preparation of lithium tetramethylcuprate(III) via rapid injection NMR," Chemical Communications, vol. 46, no. 8, pp. 12531254, 2010.

[18] S. H. Bertz, M. D. Murphy, C. A. Ogle, and A. A. Thomas, "Organocuprate(III) chemistry: synthesis and reactivity of amido, cyano, phosphido and thiolato ate complexes of copper(III)," Chemical Communications, vol. 46, no. 8, pp. 12551256, 2010.

[19] T. Gärtner, N. Yoshikai, M. Neumeier, E. Nakamura, and R. M. Gschwind, "Ligand exchange reactions in $\mathrm{Cu}(\mathrm{III})$ complexes: mechanistic insights by combined NMR and DFT studies," Chemical Communications, vol. 46, no. 25, pp. 4625-4626, 2010.

[20] G. M. Whitesides, W. F. Fischer Jr., J. San Filippo Jr., R. W. Bashe, and H. O. House, "Reaction of lithium dialkyl- and diarylcuprates with organic halides," Journal of the American Chemical Society, vol. 91, no. 17, pp. 4871-4882, 1969.

[21] I. P. Beletskaya and A. V. Cheprakov, "Copper in cross-coupling reactions: the post-Ullmann chemistry," Coordination Chemistry Reviews, vol. 248, no. 21-24, pp. 2337-2364, 2004.

[22] J. K. Kochi, "Homo coupling, disproportionation and cross coupling of alkyl groups. Role of the transition metal catalyst," Journal of Organometallic Chemistry, vol. 653, no. 1-2, pp. 11-19, 2002.

[23] A. D. Becke, "Density-functional thermochemistry. III. The role of exact exchange," The Journal of Chemical Physics, vol. 98, no. 7, pp. 5648-5652, 1993.

[24] W. J. Hehre, K. Ditchfield, and J. A. Pople, "Self-consistent molecular orbital methods. XII. Further extensions of Gaussian-type basis sets for use in molecular orbital studies of organic molecules," The Journal of Chemical Physics, vol. 56, no. 5, pp. 2257-2261, 1972.

[25] P. C. Hariharan and J. A. Pople, "Accuracy of $\mathrm{AH}_{n}$ equilibrium geometries by single determinant molecular orbital theory," Molecular Physics, vol. 27, no. 1, pp. 209-214, 1974.

[26] H. Dunning and P. J. Hay, in Modern Theoretical Chemistry, III, H. F. Schaefer, Ed., Plenum, New York, NY, USA, 1976.

[27] W. R. Wadt and P. J. Hay, "Ab initio effective core potentials for molecular calculations. Potentials for main group elements $\mathrm{Na}$ to Bi," The Journal of Chemical Physics, vol. 82, no. 1, pp. 284298, 1985.

[28] P. J. Hay and W. R. Wadt, “Ab initio effective core potentials for molecular calculations. Potentials for $\mathrm{K}$ to Au including the outermost core orbitale," The Journal of Chemical Physics, vol. 82, no. 1, pp. 299-310, 1985.
[29] P. J. Hay and W. R. Wadt, “Ab initio effective core potentials for molecular calculations. Potentials for the transition metal atoms Sc to Hg," The Journal of Chemical Physics, vol. 82, no. 1, pp. 270283,1985 .

[30] M. J. Frisch, G. W. Trucks, H. B. Schlegel et al., Gaussian 03, Revision B.03, Gaussian, Inc, Pittsburgh, Pa, USA, 2003.

[31] ADF 2006.01, SCM; Theoretical Chemistry, Vrije Universiteit, Amsterdam, Netherlands, 2006, https://www.scm.com/.

[32] E. van Lenthe, "Geometry optimizations in the zero order regular approximation for relativistic effects," The Journal of Chemical Physics, vol. 110, no. 18, pp. 8943-8953, 1999.

[33] M. Kaupp and H. G. von Schnering, "Formal Oxidation State versus Partial Charge-a Comment," Angewandte ChemieInternational Edition, vol. 34, no. 9, pp. 986-986, 1995.

[34] G. Aullón and S. Alvarez, "Oxidation states, atomic charges and orbital populations in transition metal complexes," Theoretical Chemistry Accounts, vol. 123, no. 1-2, pp. 67-73, 2009.

[35] J. P. Snyder, "Distinguishing copper $\mathrm{d}^{8}$ and $\mathrm{d}^{10}$ Configurations in a highly ionic complex; a nonformal metal oxidation state," Angewandte Chemie-International Edition, vol. 34, no. 9, pp. 986-987, 1995.

[36] S. Alvarez, R. Hoffmann, and C. Mealli, "A bonding quandaryor-a demonstration of the fact that scientists are not born with logic," Chemistry - A European Journal, vol. 15, no. 34, pp. 83588373, 2009.

[37] J. K. Bera, A. G. Samuelson, and J. Chandrasekhar, "Ab initio study of structures, energetics, and bonding in formally highoxidation-state copper organometallics," Organometallics, vol. 17, no. 19, pp. 4136-4145, 1998.

[38] P. Vijayan, P. Viswanathamurthi, K. Velmurugan et al., "Nickel(II) and copper(II) complexes constructed with $\mathrm{N}_{2} \mathrm{~S}_{2}$ hybrid benzamidine-thiosemicarbazone ligand: synthesis, $\mathrm{X}$ ray crystal structure, DFT, kinetico-catalytic and in vitro biological applications," RSC Advances, vol. 5, no. 125, pp. 103321103342, 2015.

[39] T. Koopmans, "Über die Zuordnung von Wellenfunktionen und Eigenwerten zu den Einzelnen Elektronen Eines Atoms," Physica, vol. 1, no. 1-6, pp. 104-113, 1934.

[40] R. G. Pearson, "Absolute electronegativity and hardness correlated with molecular orbital theory," Proceedings of the National Academy of Sciences of the United States of America, vol. 83, no. 22, pp. 8440-8441, 1986.

[41] S. Baskaran, P. Venuvanalingam, and C. Sivasankar, "Understanding the stability, electronic and molecular structure of some copper(III) complexes containing alkyl and non alkyl ligands: insights from DFT calculations," Journal of Organometallic Chemistry, vol. 696, no. 13, pp. 2627-2634, 2011. 

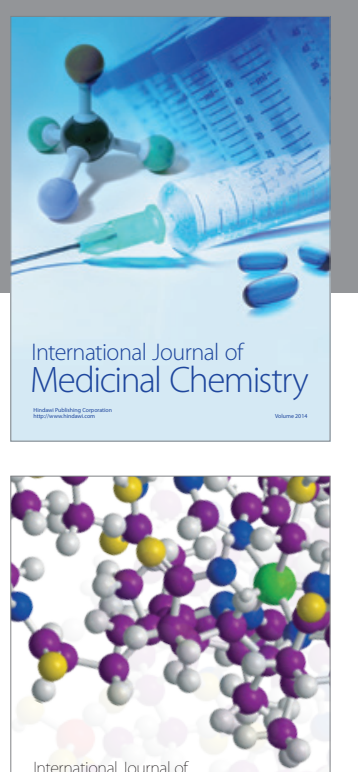

Carbohydrate Chemistry

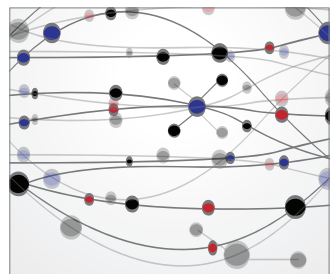

The Scientific World Journal
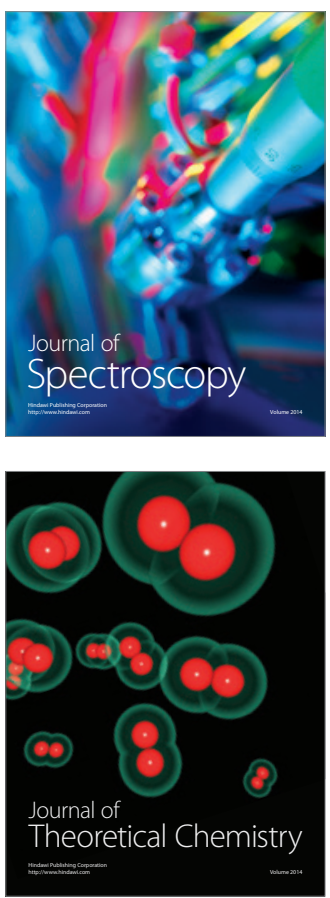
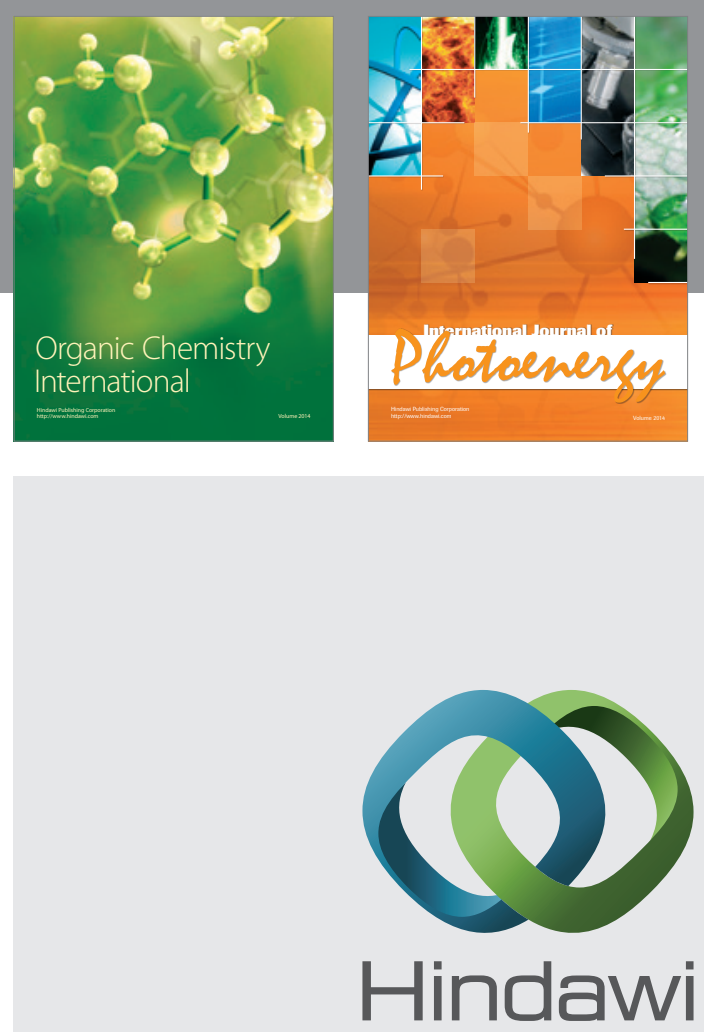

Submit your manuscripts at

http://www.hindawi.com

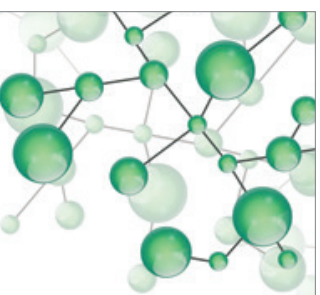

International Journal of

Inorganic Chemistry

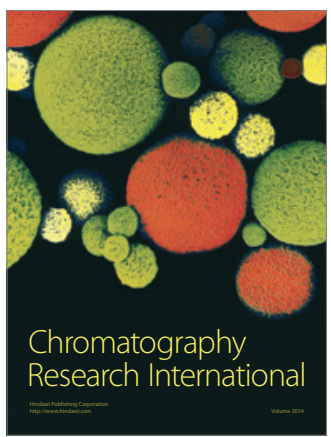

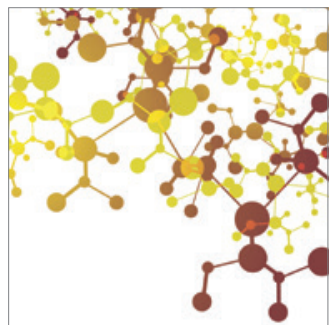

Applied Chemistry
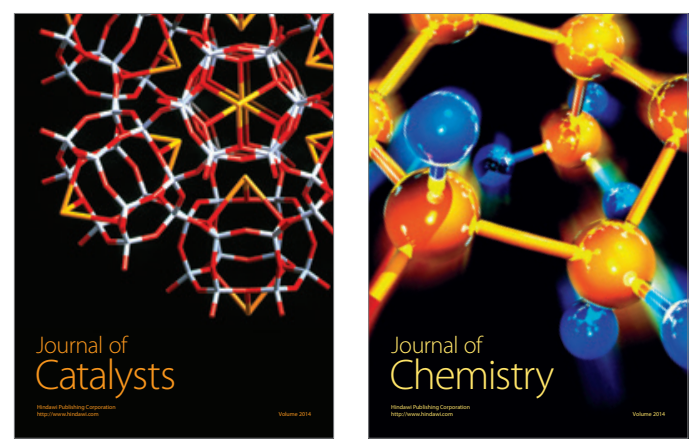
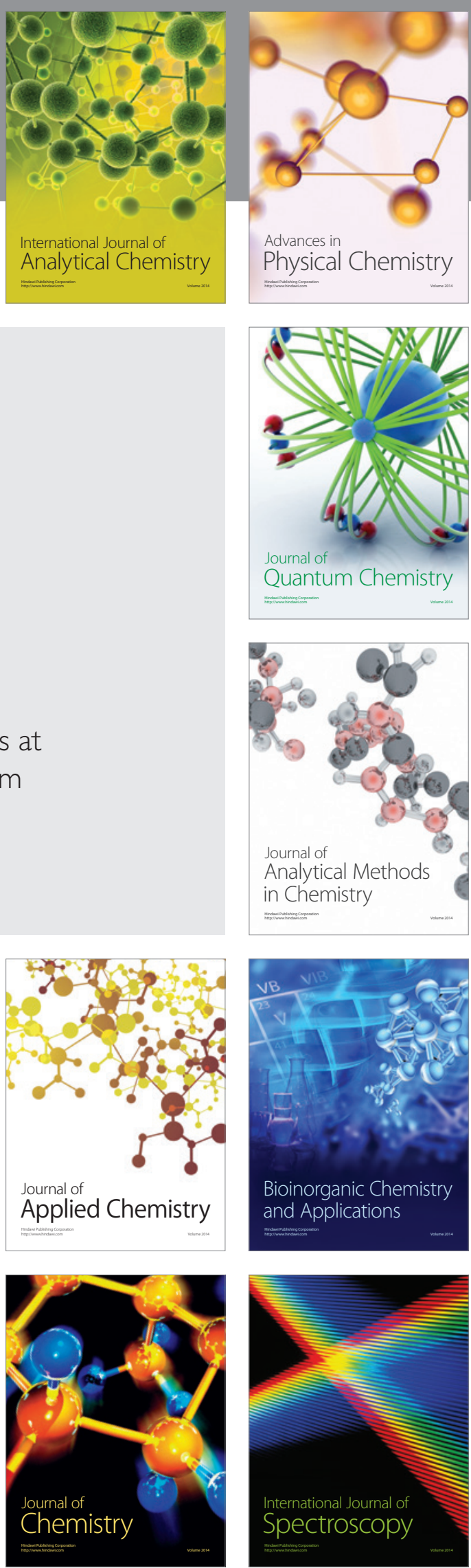